\title{
Effect of turbidity on water disinfection by chlorination with the emphasis on humic acids and chalk
}

Tangui Léziart ${ }^{1}$, Pierre-Marie Dutheil de la Rochere ${ }^{1}$, Ryan Cheswick $^{1}$, Peter Jarvis ${ }^{1}$ and Andreas Nocker $^{1,2} *$

${ }^{1}$ Cranfield Water Science Institute, Cranfield University, Cranfield, Bedfordshire, MK43

0AL, United Kingdom

${ }^{2}$ IWW Water Centre; Moritzstraße 26, 45476 Mülheim an der Ruhr, Germany

*Corresponding author: Andreas Nocker, Cranfield Water Science Institute, Cranfield

University, Cranfield, Bedfordshire MK430AL, United Kingdom; e-mail:

andreas.nocker@gmail.com

Keywords: turbidity, drinking water, chlorine disinfection, viability, flow cytometry, survival 


\section{Highlights}

- Different turbidities have different effects on chlorine disinfection

- Humic acids interfere with chlorination at $\geq 1 \mathrm{NTU}(2 \mathrm{mg} / \mathrm{L})$

- Chalk does not interfere with chlorination up to $5 \mathrm{NTU}$

- Both culture and flow cytometry lead to same conclusions 


\begin{abstract}
Chlorine is globally the most widely used chemical for water disinfection. Whereas disinfection efficiency is well known to depend on water $\mathrm{pH}$ and temperature, the effect of turbidity is less well studied. Although turbidity is measured online in most drinking water works and most countries where regulations exist have set limits of $<1$ NTU for water leaving the works, the composition of turbidity is typically unknown. Given the heterogeneous nature of substances contributing to turbidity, the aim of this work was to study the effect of selected compounds on chlorination efficacy. The effect of humic acids and chalk on the inactivation of the indicator bacteria Escherichia coli and Enterococcus faecalis was assessed at neutral $\mathrm{pH}$ at different turbidity levels using both plate counting and flow cytometry in combination with membrane integrity staining. For humic acids, a turbidity of 1 NTU (corresponding to $2 \mathrm{mg} / \mathrm{L}$ ) was identified as a critical threshold, which when exceeded was found to have a negative impact on chlorine disinfection. Chalk, on the other hand, had no measurable impact up to 5 NTU. The observation applied to both bacterial species with identical conclusions from the two diagnostic methods. Results corroborate that different turbidity causing substances affect chlorination efficiency to very different extents with chlorine demand by organic material probably being the most important determinant. In case of turbidities > 1 NTU, turbidity measurement benefits from the consideration of the organic content as mere NTU values do not allow predicting an impact on chlorination efficiency.
\end{abstract}




\section{Introduction}

Disinfection of drinking water is a critical microbiological barrier prior to water distribution. Non-compliance with regulatory water safety standards can lead to microbiologically unsafe water and can have severe consequences on public health. Among the chemical disinfectants, chlorine is by far the most commonly used agent. In addition to the well-known influences of $\mathrm{pH}$ and temperature on the efficiency of chlorination at a given dose and contact time [1], turbidity is accepted to interfere with chlorine disinfection (apart from being of aesthetic concern).

Turbidity is a measure of how much the material suspended in water decreases the passage of light through the water and is expressed in form of a uniform number (typically as nephelometric turbidity units, NTU). Turbidies are strictly regulated. In England and Wales, the maximum allowable levels for turbidity are set by the Drinking Water Inspectorate to 1 NTU for water prior to disinfection and 4 NTU for water at the consumer's tap [2]. In the European Union turbidity requirements are $<1$ NTU for surface water post treatment (European Union (Drinking Water Regulations 2014), whereas in the US turbidity should not go above 5 NTUs at any time and must be $\leq 0.3$ NTUs in at least $95 \%$ of samples in any month for systems that use conventional and direct filtration (Long Term 1 Enhanced Surface Water Treatment Rule (LT1ESWTR, 2002). WHO eventually suggests that turbitity of drinking water should at no point exceed 5 NTUs and should preferably be less than 1 NTU [3]. A turbidity threshold of below $0.2 \mathrm{NTU}$ is promoted (WHO, 2011). To reduce turbidity to these levels, water treatment facilities need an appropriate removal capacity depending on the turbidity range of the corresponding raw waters [4]. Whereas groundwaters tend to have very low turbidities, the turbidities of surface waters can be high and subject to great variation.

Turbidity is composed of a heterogeneous mixture of different particle types and materials present in water in the form of particulates, colloids and dissolved materials. 
Turbidity causing materials (TCMs) can be of inorganic and organic nature. They are either naturally present in water or can be introduced into drinking water via the water treatment process $[5,6]$. Important natural TCMs include natural organic matter (NOM, humic and nonhumic), sediments, clay, chalk, sand and biomass such as bacteria, plankton, algae or biofilm $[7,8,9]$. TCMs introduced during water treatment (from insufficient clarification) include chemical flocs formed by the addition of metal salts such as $\mathrm{Al}^{3+}$ and $\mathrm{Fe}^{3+}$ coagulants [10]. Turbidity can also originate from precipitates caused by changes in the water $\mathrm{pH}$ or through chemical reactions. Whereas turbidity is mostly regulated as its presence, apart from aesthetic concerns, is often associated with elevated levels of pathogens, knowledge to what extent these different substances impact chlorine disinfection is very limited. Due to their heterogeneous nature, TCMs can be assumed to have very different effects on disinfection efficiency. It has been stated from as early as 1978 that the 'interference of turbidity with disinfection depends more on the types of turbidity present than on the number of turbidity units present' [11]. However, there is little direct evidence supporting this view.

In this study the chlorine demand of a range of TCMs was measured across turbidity gradients. Humic acids and chalk were then selected as representative TCMs with high and low chlorine demands respectively to take forward for disinfection testing. Whereas humic acids are comprised of complex water-soluble polymers and represent the major fraction of organic matter in natural water [12], chalk carbonates are common in karstic areas [13]. The aim was to identify whether and at which turbidity values the presence of these substances interferes with disinfection efficacy. The effect on chlorination efficiency was studied using two important microbiological water quality indicators (Escherichia coli and Enterococcus faecalis). Both cultivation and flow cytometry (in combination with cell membrane integrity staining) as a cultivation-independent diagnostic tool for viability assessment were applied with the intention to assess the comparability of results. 


\section{Materials and methods}

\subsection{Preparation of turbidity and chlorine solutions}

Stock solutions (approx. 100 NTU) of humic acids (Sigma-Aldrich, UK, CAT: H16752), manganese dioxide (Sigma-Aldrich, CAT: 13242) and chalk (calcium carbonate, Fischer Scientific, UK, CAT: C/1040/60) were made by dissolving commercial powders in filtered $(0.2 \mu \mathrm{m})$ mineral water (Evian, Evian-les-bains, France). Fe(III) hydroxide precipitate was produced by dissolving $\mathrm{FeCl}_{3}$ (Sigma-Aldrich, CAT: 15774-0) in ultrapure (UP) water (Ultra GE MK2 Purelab, Elga, High Wycombe, Buckinghamshire, UK) at a concentration of 25 $\mathrm{mg} / \mathrm{L}$ at $\mathrm{pH} 4.5$. The $\mathrm{pH}$ was subsequently adjusted to 7 using $0.1 \mathrm{M} \mathrm{NaOH}$ solution and the resulting Fe(III) hydroxide precipitate was washed three times in UP water, separated by centrifugation $(1,000 \mathrm{xg})$ and re-suspended in filtered mineral water. Stock solutions were further diluted with filtered mineral water to turbidity levels two-fold (for assessing chlorine demand) or four-fold (humic acids and chalk for the bacterial inactivation experiments) higher than the desired final turbidity levels. In case of humic acids and chalk the final turbidity values were $0,0.1,0.2,0.4,1,2$, and 5 NTU to cover the extremes of turbidity that may be given in drinking water. Turbidities of all solutions were verified using a turbidimeter (Hach $2100 \mathrm{~N}$ turbidimeter, Salford M50 1DL, UK). All pH values were adjusted to neutral $\mathrm{pH} 7.0$ if necessary.

The chlorine gradient of $0,0.01,0.02,0.1,0.25,0.5,0.75$ and $1 \mathrm{mg} \mathrm{L}^{-1}$ used in the study to assess bacterial inactivation was made by stepwise dilution of a chlorine stock solution of $11.15 \%$ (Sigma Aldrich, St. Louis, MO, USA) with UP water to a concentration of $100 \mathrm{mg}$ $\mathrm{L}^{-1}$. This concentrated chlorine solution was further stepwise diluted with filtered mineral water (to ensure osmotic balance when added to the bacterial suspensions) to working concentrations four-fold higher than the desired final concentrations. All solutions were made 
in chlorine demand-free glassware. The free chlorine concentration of the chlorine stock and the correctness of the $100 \mathrm{mg} \mathrm{L}^{-1}$ dilution were measured prior to every experiment using a pocket colorimeter (Hach-Lange, Salford, UK) and DPD sachets (Hach, Salford, UK; free chlorine reagent powder pillows, product nr. 2105569) after appropriate dilution to meet the adequate measurement range $<2 \mathrm{mg} \mathrm{L}^{-1}$. The mineral water only exerted negligible chlorine demand in the time necessary to perform the corresponding experiments.

\subsection{Preparation of chlorine demand-free glassware}

Borosilicate glassware was machine-washed and rinsed three times with ultrapure water. It was then filled with $0.2 \mathrm{~N}$ hydrochloric acid and incubated overnight to allow for acid hydrolysis followed by repeated thorough rinsing (three times) with ultra pure water. Glassware was subsequently air dried, covered with aluminum foil and heated at $550^{\circ} \mathrm{C}$ for at least 6 hours in a muffle oven (Muffle Furnace 1400, PaveTesting Ltd, Hertfordshire, UK). Glassware was stored in a dry place away from sunlight until use.

\subsection{Assessment of chlorine demand kinetics}

Solutions $(250 \mathrm{~mL})$ of defined turbidity $1 \mathrm{NTU}$ of selected TCMs were prepared with filtered $(0.2 \mu \mathrm{m})$ mineral water in $250 \mathrm{~mL}$ chlorine demand-free Erlenmeyer flasks. Samples were supplemented with a small volume of diluted chlorine stock (approx. 2,000 $\mathrm{mg} \mathrm{L}^{-1}$ free chlorine) to obtain a disinfectant concentration of $1 \mathrm{mg} \mathrm{L}^{-1}\left( \pm 0.05 \mathrm{mg} \mathrm{L}^{-1}\right)$ free chlorine. Flasks were shaken at $290 \mathrm{rpm}$ at room temperature $\left(20 \pm 2^{\circ} \mathrm{C}\right)$. Aliquots of $10 \mathrm{~mL}$ were taken at different times (up to $30 \mathrm{~min}$ ) and assessed for free and total chlorine using a pocket colorimeter (Hach-Lange, Salford, UK). For this the water was mixed with the contents of a DPD sachet (Hach, Salford, UK; free chlorine reagent powder pillows, product nr. 2105569; total chlorine reagent powder pillows, product nr. 2105628) in a measurement cuvette, swirled 
for 30 seconds and measured after one min and three min incubation, respectively, as outlined in the instructions by the manufacturer.

\subsection{Bacterial strains and growth conditions}

Escherichia coli (E. coli; ATCC 25922) and Enterococcus faecalis (E. faecalis; ATCC 29212) were grown at $35^{\circ} \mathrm{C}$ in $10 \%$ Tryptone Soya Broth (TSB CM0129, Oxoid, Basingstoke, Hampshire, UK) for 15 hours at $290 \mathrm{rpm}$. The resulting E. coli culture was adjusted to an optical density $\left(\mathrm{OD}_{600}\right)$ (Jenway 6310, Essex, UK) of 1.0 using pre-warmed 10\% TSB. This optical density corresponds to a bacterial concentration of $10^{9}$ E. coli cells $\mathrm{mL}^{-1}$. Cell aliquots of $1 \mathrm{~mL}$ were subsequently harvested by centrifugation $(5,000 \mathrm{~g}, 5 \mathrm{~min})$ and the supernatant carefully removed with a tip. The E. coli pellet was washed three times by resuspension in 0.2 $\mu \mathrm{m}$ filtered mineral water to remove chlorine demand. E. coli cells were subsequently diluted 100-fold by adding $100 \mu \mathrm{L}$ of bacterial suspension to $9.9 \mathrm{~mL}$ of filtered mineral water (to obtain a concentration of $10^{7}$ cells $\mathrm{mL}^{-1}$ ) followed by another 50 - fold dilution resulting in a suspension of $2 \times 10^{5}$ cells $\mathrm{mL}^{-1}$. The E. faecalis culture was adjusted to an $\mathrm{OD}_{600}$ of 0.4 using $10 \%$ TSB. This optical density corresponded to $8 \times 10^{6}$ E. faecalis cells $\mathrm{mL}^{-1}$. Aliquots $(1 \mathrm{~mL})$ of these suspensions were subsequently pelleted by centrifugation $(5,000 \mathrm{~g}, 5 \mathrm{~min})$, followed by careful removal of the supernatant with a pipette tip and resuspension of the bacterial pellet in filtered mineral water. This washing was done three times. The bacterial suspension was eventually diluted 80 -fold by mixing $0.1 \mathrm{~mL}$ of bacterial suspension with $7.9 \mathrm{~mL}$ of filtered Evian to a concentration of $10^{6}$ cells $\mathrm{mL}^{-1}$ followed by another 5 -fold dilution to obtain $2 \times 10^{5}$ cells $\mathrm{mL}^{-1}$. The $\mathrm{pH}$ of the suspensions was 7.2. 


\subsection{Disinfection in absence of TCMs}

Disinfection experiments were performed in a laminar flow hood by adding aliquots of 100 $\mu \mathrm{L}$ bacterial suspensions $\left(2 \times 10^{5}\right.$ cells $\left.\mathrm{mL}^{-1}\right)$ to the wells of a chlorine demand-free 96 -well glass plate (Zinsser NA Inc., Northridge, USA) containing $50 \mu \mathrm{L}$ pre-aliquoted filtered mineral water and $50 \mu \mathrm{L}$ chlorine solution (at concentrations four-fold higher than the desired final concentration). Final chlorine concentrations were $0.01,0.05,0.1,0.25,0.5,0.75$ and 1 $\mathrm{mg} \mathrm{\textrm {L } ^ { - 1 }}$ and the final bacterial concentration was $10^{5}$ cells $\mathrm{mL}^{-1}$. Samples without chlorine served as controls. The plates were shaken for 30 minutes at $290 \mathrm{rpm}$. The well contents were subsequently transferred into 96-well plastic plates (Porvair Sciences Ltd, Wales, UK) containing $2 \mu \mathrm{L}$ of pre-aliquoted $0.1 \mathrm{~N}$ thiosulfate (Acros Organics, Geel, Belgium) per well to quench the chlorine and were thoroughly mixed by pipetting up and down several times using a multichannel pipette. 


\subsection{Disinfection in presence of TCMs}

For disinfection in the presence of turbidity, aliquots of $110 \mu \mathrm{L}$ of bacterial suspension $\left(2 \times 10^{5}\right.$ cells $\mathrm{mL}^{-1}$ ) were added to the wells of round-bottom plastic plates containing $55 \mu \mathrm{L}$ of prealiquoted humic acid or chalk solutions at a turbidity level four-fold higher than the desired final turbidity during disinfection to compensate for subsequent dilution in the final mixture. The plates were shaken at $290 \mathrm{rpm}$ for 2 hours at room temperature $\left(20 \pm 2^{\circ} \mathrm{C}\right)$ to allow for potential attachment of the bacteria to any particulates. Volumes of $150 \mu \mathrm{L}$ of these mixtures were subsequently transferred to the wells of a chlorine demand-free 96-well glass plate with each well containing $50 \mu \mathrm{L}$ of chlorine solution (also with concentrations four-fold higher than the desired final chlorine concentration). Final concentrations were as follows for TCMs: $0 ; 0.1 ; 0.2 ; 0.4 ; 1 ; 2 ; 5 \mathrm{NTU}$, for chlorine: $0,0.01,0.05,0.1,0.25,0.5,0.75,1 \mathrm{mg} \mathrm{L}^{-1}$; and for bacteria at $10^{5}$ cells $\mathrm{mL}^{-1}$. The $\mathrm{pH}$ values were between 7.0 and 7.2. Glass plates were shaken for 30 minutes followed by transfer of $200 \mu \mathrm{L}$ well contents into plastic plates with prealiuoted thiosulfate to quench the chlorine (as described before).

\subsection{Viability assessment by spot plating}

The impact of chlorination on bacterial viability was assessed using a drop spotting method as described by Nocker et al. [14]. Using a multichannel pipette, volumes of $1 \mu \mathrm{L}$ (100 cells) of the quenched samples (located in the wells of a 96 well plate) were spotted in a grid format onto a nutrient agar square plate (Greiner square dish, 120 × 120 × 17mm, Sigma-Aldrich, UK, CAT. Z 617679). Membrane Lactose Glucuronide Agar (MLGA CM1031, Oxoid, Hampshire, UK) and MacConkey (CM0007; Oxoid, Hampshire, UK) were used as growth media for E. coli and E. faecalis, respectively. Droplets were allowed to soak into the agar plate for $5 \mathrm{~min}$ prior to reversing the plates for incubation for 16 hours at $35^{\circ} \mathrm{C}$. Pictures of 
plates were made on a ProXima C16 Phi+imaging system (Isogen Life Science, Netherlands) using the following grayscale settings: exposure $40 \mathrm{~ms}$, zoom 3.0, iris 3.1, focus 84, no filter.

\subsection{Flow cytometric analysis}

Fluorescence staining was carried out following the protocol developed by Hammes et al. (2008) with a few amendments. In order to quantify total cell counts (TCCs), a 10,000x stock of SYBR Green I (CAT S-7567; Life Technologies Ltd., Paisley, UK) was diluted with dimethyl sulphoxide (DMSO) (Fisher Scientific, Fair Law, NJ) to obtain a 100× working stock solution. Aliquots of $1 \mu \mathrm{L}$ of this dye solution were pre-aliquoted in the wells of a 96 well plate (Porvair Sciences Ltd, Wales, UK) followed by addition of sample (volumes of 100 $\mu \mathrm{L}$ ) for staining at a $1 \mathrm{x}$ final SYBR Green concentration using a multichannel pipette. Mixing was achieved by pipetting down several times. For the quantification of intact cell concentrations (ICCs), a dye mixture was made of SYBR Green I (100x) and propidium iodide (PI; $1 \mathrm{mg} \mathrm{mL}^{-1}$, corresponding to $1.5 \mathrm{mM}$; CAT P3566; Life Technologies Ltd, Paisley, UK) at a ratio of 5:1. Volumes of $1.2 \mu \mathrm{L}$ of this dye mixture were pre-aliquoted into the wells of a 96 well plate followed by addition of $100 \mu \mathrm{L}$ of sample to give a final dye concentrations of $1 \times$ and $3 \mu \mathrm{M}$ for SYBR Green I and PI, respectively. The mixtures were subsequently incubated at $37^{\circ} \mathrm{C}$ for 13 minutes in a Grant-bio PHMP thermo-shaker (Grant Instruments Ltd, Cambridgeshire, UK) at $600 \mathrm{rpm}$. Samples were analyzed using a BD Accuri C6 cytometer (Becton Dickinson UK Ltd., Oxford, UK) equipped with a $488 \mathrm{~nm}$ laser. All analyses were carried out in triplicates. Analyzed volumes were $25 \mu \mathrm{L}$ with the trigger set on FL-1. The flow rate was set to 'fast' corresponding to $66 \mu \mathrm{L} \mathrm{min}{ }^{-1}$. FL-1 signals smaller than 800 fluorescence units were excluded from analysis. TCC and ICC signals were analyzed using the FL3 (red fluorescence, $670 \mathrm{~nm}$ ) vs FL1 (green fluorescence, $533 \mathrm{~nm}$ ) density plots. 


\subsection{Statistical analysis}

At least three independent repeats were carried out for every experiment. Data for chlorine demand kinetics is shown with error bars reflecting standard deviations (calculated in Excel and Statistica). Representative images are shown for spot plating results. Color schemes showing flow cytometric results are based on averages from at least three experiments.

\section{Results}

\subsection{Chlorine demand of selected TCMs}

In a first experiment the chlorine demand of five important TCMs (humic acids, $\mathrm{Fe}^{3+}$, chalk, kaolin clay and $\mathrm{MnO}_{2}$ ) was determined by supplementing TCM solutions of 1 NTU with chlorine (initial concentration of $1 \mathrm{mg} \mathrm{L}^{-1}$ free chlorine). Among the five TCMs, only humic acids (as the only organic substance) was found to react strongly with around half of the free chlorine being consumed after 1 to $2 \mathrm{~min}$ (Fig. 1). Chlorine inactivation subsequently slowed following concentration-dependent first order kinetics and eventually stopped when all chlorine had been consumed. The inorganic substances did not show chlorine inactivation over $30 \mathrm{~min}$. The apparently slight increase in chlorine demand was shown to be caused by their interference with chlorine measurement. Measurement of total chlorine followed the same trend with concentration values being nearly identical with the ones of the free chlorine (data not shown).

\subsection{Assessment of bacterial inactivation by flow cytometry}

Suspensions of E. coli and E. faecalis $\left(10^{5} \mathrm{CFU} \mathrm{mL} \mathrm{m}^{-1}\right)$ were exposed to increasing chlorine concentrations for 30 min followed by quenching of the disinfectant with thiosulfate, membrane integrity staining and analysis by flow cytometry. The extent of membrane damage 
was visualized on FL1/FL3 density plots (Fig. 2). Membrane damage inflicted to E. coli was gradual. Whereas bacteria appeared intact at $0.05 \mathrm{mg} \mathrm{L}^{-1}$, a signal transition to a region indicating moderate membrane damage was observed at 0.1 and $0.25 \mathrm{mg} \mathrm{L}^{-1}$ chlorine. At higher disinfectant concentrations all signals were located in the area that is characteristic of significant membrane damage. The transition was captured by defining two flow cytometric gates (Fig. 2A). In the case of E. faecalis, signals underwent a more abrupt transition from intact to strongly damaged when increasing the chlorine concentration from 0.1 to $0.25 \mathrm{mg} \mathrm{L}^{-1}$ with no intermediate damage status visible with the chosen resolution of the disinfectant gradient. Due to the lack of a transitory membrane integrity status, only one gate was defined for this reason for E. faecalis. This gating strategy was applied to the following experiments.

\subsection{Disinfection efficacy in presence of humic acids}

In the next stage of the work, bacterial suspensions were subjected to the chlorine concentration gradient in the presence of increasing turbidities of humic acids. Bacteria were exposed to chlorine for $30 \mathrm{~min}$ followed by neutralization of the disinfectant. Samples without humic acids and/or without chlorine served as controls. Aliquots from this experimental grid were subsequently analyzed by cultivation (spot plating) and flow cytometry. For E. coli, viability was not affected by chlorine concentrations up to $0.05 \mathrm{mg} \mathrm{L}^{-1}$ as bacteria both grew on nutrient agar and had intact cell membranes (Fig. 3A). Culturability was affected at $0.1 \mathrm{mg}$ $\mathrm{L}^{-1}$ chlorine at turbidity values up to $0.4 \mathrm{NTU}$, whereas at higher turbidities $(\geq 1 \mathrm{NTU}$, corresponding to $2 \mathrm{mg} / \mathrm{L}$ ) of humic acids bacterial growth was observed. The loss of disinfection efficacy at turbidities $\geq 1$ NTU was corroborated by membrane integrity staining, although the effect was seen at a higher chlorine threshold of $0.25 \mathrm{mg} \mathrm{L}^{-1}$. It is known that higher chlorine concentrations are necessary to inflict membrane damage than to compromise culturability [15]. At higher turbidities increasing proportions of bacteria maintained 
membrane integrity as indicated by the green color. In other words, higher humic acid concentrations had the consequence that more chlorine was necessary to achieve membrane damage.

The same tendencies were observed for E. faecalis. At $0.1 \mathrm{mg} \mathrm{L}^{-1}$ initial free chlorine, colony formation became visible again in the presence in the presence of humic acid turbidity $\geq 1 \mathrm{NTU}$ (Fig. 3B). In case of membrane integrity, this applied at free chlorine of $0.25 \mathrm{mg} \mathrm{L}$ ${ }^{1}$. Although, like in the case of E. coli, more chlorine was therefore necessary to induce membrane damage compared to culturability, it could be concluded also with this bacterial species that humic acids at turbidities $\geq 1$ NTU can interfere with chlorine disinfection.

\subsection{Disinfection efficacy in presence of chalk}

In line with experiments with humic acids, a grid system of increasing chlorine concentrations and chalk turbidities was applied to both E. coli (Fig. 4A) and E. faecalis (Fig. 4B). For chalk, no loss of disinfection efficacy was observed along the entire turbidity gradient, by both culture and flow cytometry. However, as seen for humic acid, higher chlorine concentrations were needed to inflict membrane damage than to affect culturability. For chalk, a clear loss of culturability/integrity was observed at 0.1 and $0.25 \mathrm{mg} \mathrm{L}^{-1}$ free chlorine for culture and flow cytometry methods, respectively, regardless of the turbidity level in the sample. It was concluded that chalk did not compromise chlorine efficacy at turbidity values up to 5 NTU. 


\section{Discussion}

Humic acids and chalk were chosen in this study as representatives of TCMs with and without a chlorine demand to assess whether they interfere with chlorine disinfection efficacy. The obtained results support the hypothesis that different substances contributing to turbidity have different effects on chemical disinfection. Whereas humic acids clearly weakened the effect of chlorine at higher turbidity levels, chalk did not show a dose-response relationship. In the case of suspended turbidity, data suggests that the impact on chlorine is primarily caused by substances with a chlorine demand. The humic acids used in this study reacted with chlorine within minutes. Their presence nevertheless only negatively impacted disinfection efficacy at turbidities values $\geq 1$ NTU. Humic acids that are mainly found in surface waters [16] can be assumed not to be present at such high levels in the final disinfection step as for the purpose of drinking water production surface water-impacted raw water undergoes multistep treatment. When complying with WHO or national guidelines requiring turbidities of water prior to disinfection to be $<1 \mathrm{NTU}$, these results are reassuring for drinking water process operators even in the unlikely case that all turbidity were composed of such organics reacting with chlorine. It should be noted that the humic acid product used in this study was of natural origin resulting from the decomposition of organic matter (particularly dead plants, MW 2,000 - 500,000 Da). The term "humic acid" is however generic and refers to the fraction of soil organic material soluble in alkaline solutions but not in acid or ethyl alcohol [17]. Most of the chlorine consumption was reported to be due to the reaction with activated aromatic structures, however different humic acids show different reactivities mainly due to their nitrogen content and humic acids were found to be more reactive with chlorine than fulvic acids [18].

It is unclear how many of the vast diversity of organic compounds have light scattering properties and thus contribute to turbidity (as measured in NTU). As early as 1976, 
a list of 1259 organic compounds identified in water has been published [19]. Amino acids have been reported to be some of most reactive organic compounds, whereas some humic acids show low reactivity [20]. A detailed review about the reactivities of organic and inorganic compounds with chlorine was presented by Deborde and von Gunten [21]. Despite the enormous diversity of organics in water, humic substances tend to represent $50-90 \%$ of dissolved organic material in surface waters [22] and therefore deserve special attention. An indication about the extent of organic content within the turbidity pool can be obtained by spectrophotometric analysis in the UV range (e.g. UV 254; due to absorption of nucleic acids, aromatic amino acids and humic and fulvic acids) or directly by measuring the TOC or DOC content. Apart from the nature of the organic compound, reactivity also depends on other parameters like $\mathrm{pH}$ or the ratio of chlorine to substrate [22].

The low chlorine reactivity of the inorganic TCMs chalk, Fe (III), $\mathrm{Mn}^{2+}$ and kaolin clay is in line with previous reports of low reactivity at neutral $\mathrm{pH}$ [21]. It is tempting to explain the lack of a dose-response relationship in the disinfection experiment with the lack of a chlorine demand within the studied time frame of $30 \mathrm{~min}$. Nevertheless other parameters given in disinfection of real water in water treatment works have to be considered. Factors like bacterial attachment to particles and aggregate sizes as occurring in real water need further assessment. Despite co-incubation of bacteria with TCMs on a shaker over 2 hours to allow for attachment, stronger protection of bacteria from chlorination by TCMs through stronger interactions (e.g. complete masking by inclusion of bacteria in aggregates) cannot be ruled out from this study. Microbial attachment to surfaces is driven by complex multivariate factors including electrostatic interactions, van der Waals forces, hydrophobicity, surface tension and surface roughness $[23,24,25]$ that are difficult to be simulated. Also the particle size is critical in protection of particle associated microorganisms. When studying the susceptibility of indigeneous coliforms from primary sewage effluent, bacteria that were associated with the $<7 \mu \mathrm{m}$ particle fraction were found to be more rapidly inactivated by 0.5 
$\mathrm{mg} \mathrm{L}^{-1}$ chlorine $\left(5^{\circ} \mathrm{C}, \mathrm{pH} 7\right)$ than coliforms associated with the $>7 \mu \mathrm{m}$ fraction [26]. Homogenization of the $>7 \mu \mathrm{m}$ fraction (resulting in particle dispersal) gave a coliform inactivation rate similar to the one observed for the smaller particle fraction. None of the generated particles in this study exceeded $6 \mu \mathrm{m}$ [27], which could potentially explain the absence of protective effects other than chlorine demand. Disinfectant demand associated with organic carbon concentrations have also been reported to be an important parameter in one of the first studies reporting a correlation between turbidity and chlorine disinfection efficiency [28]. When examining coliform inactivation, a 4-log reduction in culturable cells was obtained at a turbidity of 1.5 NTU. Increasing the turbidity to 13 NTU, coliform inactivation efficiency dropped to 1-log under the conditions chosen. Total organic carbon was shown to interfere with the maintenance of a free chlorine residual. Turbidity control to 1- 5 NTU was suggested to be necessary to maintain adequate chlorine disinfection efficiency. This result holds true for waters with a clear correlation between turbidity and chlorine demand by TOC, but such a correlation must not always be given when turbidity is caused by substances without chlorine demand (Lantagne et al. 2008). A laboratory study by Wilhelm et al. (2018) where turbidity was artificially created by addition of kaolin clay showed that such demand-free turbidity did not have an effect on the log reduction of E. coli. No substantial differences in chlorination efficiency were reported when comparing water adjusted to turbidities of 10, 100 and 300 NTU. In cases where turbidity and chlorine demand is not correlated, mere turbidity values are thus not meaningful for predicting the efficiency of chlorine disinfection. Rathermore residual chlorine needs to be measured to ensure that an appropriate residual is maintained.

Comparing the two analytical methods applied here, the overall conclusions were identical. Although the sensitivity towards free chlorine was stronger in the case of cultivation, the relative impact of turbidity on disinfection efficiency showed the same pattern increasing the confidence in the data. Monitoring membrane damage as an indirect viability 
parameter can be seen a convenient analytical alternative to cultivation due to the fact that the data is obtained much faster and due to the compatibility of the method with automation.

\section{Conclusions}

This study identified pronounced differences between different TCMs in regard to their effect on chlorine-based disinfection. Whereas humic acids were found to have an effect at turbidity levels $\geq 1$ NTU, the presence of chalk did not show any effect up to 5 NTU. The result is reassuring as within the permitted turbidity range of finished water, little effect on chlorination efficiency could be seen. The study thus corroborates the maximal turbidity limit of 1 NTU for finished drinking water. When treating waters with higher turbidities, better knowledge about the composition of the turbidity can be seen greatly beneficial to judge its impact on disinfection. Determination of the UV254 value as an indicator of organic content or direct determination of TOC or DOC appear useful to gain information about the organic content contributing to turbidity and to predict a possible interference with chlorination efficacy. Ideally the chlorine residual is measured. Furthermore, flow cytometric assessment of disinfection efficacy provided the same conclusions as cultivation with the benefit of much faster data availability. Directly measuring bacterial damage would help to avoid chemical overdosing and trim disinfection-by-products from excess use of chlorine.

\section{Acknowledgements}

This work was funded by the UK Water Industry Research Limited (UKWIR) under funding provision 16/DW/02/79. The authors were commissioned and funded by UKWIR to carry out this research, which was reported as a chapter presented within a technical report. The funding agency did not influence the content of this paper. 


\section{REFERENCES}

[1] White GC. Handbook of chlorination and alternative disinfectants (4th edn.) WileyInterscience, John Wiley and Sons Inc., NY; 1999.

[2] Drinking Water Inspectorate. Guidance on the implementation of the water supply (water quality) regulations 2000 (as amended in England). DWI Guidance Document. Version 1.1.; 2010 .

European Union (Drinking Water) Regulations 2014

[3] WHO. Guidelines for Drinking-water Quality, Fourth edition, World Health Organization, Geneva; 2011.

[4] Moore WB, McCarl BA. Off-site costs of soil erosion: a case study in the Willamette Valley. Western J. Agricul. Econ. 1987;12:42-49.

[5] Gauthier V, Barbeau B, Tremblay G, Millette R, Bernier AM. Impact of raw water turbidity fluctuations on drinking water quality in a distribution system. J. Environ. Eng. Sci. $2003 ; 2: 281-291$.

[6] Matilainen A, Vepsäläinen M, Sillanpää M. Natural organic matter removal by coagulation during drinking water treatment: A review. Advan. Colloid Interface Science 2010;159:189-197.

[7] Helbling DE, Van Briesen JM. Free chlorine demand and cell survival of microbial suspensions. Water Res. 2007; 41: 4424-4434.

[8] Huber SA. Significance, origin, and fate of natural organic matter in boiler feedwater preparation using surface water. Ultrapure Water 2002;19:18-24.

[9] Valdes D, Dupont JP, Laignel B, Slimani S, Delbart C. Infiltration processes in karstic chalk investigated through a spatial analysis of the geochemical properties of the groundwater: The effect of the superficial layer of clay-with-flints. J. Hydrol. 2014;519:23-33. 
[10] Sillanpää M, Ncibi MC, Matilainen A, Vepsäläinen M. Removal of natural organic matter in drinking water treatment by coagulation: A comprehensive review. Chemosphere 2018; 190:54-71.

[11] Hoff JC. The relationship of turbidity to disinfection of potable water. p. 103-117. In C. W. Hendricks (ed.), Evaluation of the microbiology standards for drinking water. U.S. Environmental Protection Agency, Washington, D.C.; 1978.

[12] Kopfler F, Ringhand H, Coleman W, Meier J. Reactions of chlorine in drinking water, with humic acids and 'in vivo'. U.S. Environmental Protection Agency, Washington, D.C., EPA/600/D-84/196 (NTIS PB85160737); 2002.

[13] Rico G, Juignet P, Meyer R. Water turbidity in chalk aquifers in Normandy: a genuine tracer. Comptes Rendus - Academie des Sciences, Serie II. 1993;316:225-230.

[14] Nocker A, Sossa Fernández P, Montijn R, Schuren F. Effect of air drying on bacterial viability: A multiparameter viability assessment. J. Microbiol. Methods 2012;90:86-95.

[15] Virto R, Mañas P, Alvarez I, Condon S, Raso J. Membrane damage and microbial inactivation by chlorine in the absence and presence of a chlorine-demanding substrate. Appl. Environ. Microbiol. 2005; 71:5022-5028.

[16] Rodrigues A, Brito A, Janknecht P, Proenca MF, Nogueira R. Quantification of humic acids in surface water: effects of divalent cations, $\mathrm{pH}$, and filtration. J. Environ. Monit. 2009; $11: 377-382$.

[17] Christman RR, Oglesby RT. Microbiological degradation and the formation of humus. In: Sarkanen KV and Ludwig CH, eds. Lignins: Occurrence, Formation, Structure, and Reactions. Wiley Interscience Publishers, New York; 1971; 769-795.

[18] Reckhow DA, Singer PC, Malcolm RL. Chlorination of humic materials: byproduct formation and chemical interpretations. Environ. Sci. Technol. 1990;24:1655-1664. 
[19] Schakelford WM, Keith LH. Frequency of organic compound found in water. US Environmental Protection Agency. Document EPA-600/4-76-062; 1976.

[20] Katz EL. Reactivity of nitrogenous and other organic compounds with aqueous chlorine. Bull. Environ. Contam. Toxicol. 1986;36:715-722.

[21] Deborde M, von Gunten U. Reactions of chlorine with inorganic and organic compounds during water treatment—Kinetics and mechanisms: A critical review. Water Res 2008; $42: 13-51$.

[22] Fielding M, Haley J, Watts CD, Corless C, Graham NJD, Perry R. The effect of chlorine and ozone on organic compounds in water - a literature review. Water Res. Cent. PRD 1217-M; 1987.

[23] Gerba CP. Applied and theoretical aspects of virus adsorption to surfaces. Adv. Appl. Microbiol. 1984;30:133-168.

[24] Liu G, Ling FQ, Magic-Knezev A, Liu WT, Verberk JQJC, Van Dijk JC. Quantification and identification of particle-associated bacteria in unchlorinated drinking water from three treatment plants by cultivation-independent methods. Water Res. 2013;47:35233533.

[25] Mamane-Gravetz H, Linden KG. Relationship between physiochemical properties, aggregation and U.V. inactivation of isolated indigenous spores in water. J. Appl. Microbiol. 2005;98:351-363.

[26] Berman D, Rice EW, Hoff JC. Inactivation of particle-associated coliforms by chlorine and monochloramine. Appl. Environ. Microbiol. 1988;54:507-512.

[27] Farrell C, Hassard F, Jefferson B, Leziart T, Nocker A, Jarvis P. Turbidity composition and the relationship with microbial attachment and UV inactivation efficacy. Sci. Total Environ. 2017;19:638-647.

[28] LeChevallier MW, Evans TM, Seidler RJ. Effect of turbidity on chlorination efficiency and bacterial persistence in drinking water. Appl. Environ. Microbiol. 1981;42:159-167. 


\section{Figure legends}

Fig. 1. Chlorine consumption kinetics of five selected TCMs (1 NTU each) mixed with chlorine ( $1 \mathrm{mg} \mathrm{L}^{-1}$ initial concentration at time point zero). Concentrations of free chlorine were measured at time points 0 and after 1, 2, 5, 10, 20 and 30 min.

Fig. 2. Effect of chlorine on flow cytometric profiles of E. coli and E. faecalis. (A) Gates used to assess the extent of membrane damage. Two gates (defined by dotted lines) were used in case of $E$. coli where a transition from intact via moderately damaged (intermediate) to strongly damaged bacteria could be well differentiated. One gate was used for E. faecalis as the transition from intact to damaged was more abrupt. (B) Change of FCM patterns after exposing bacteria to different chlorine concentrations for $30 \mathrm{~min}$ followed by neutralization of the disinfectant and membrane integrity staining. Non-treated suspensions without chlorine serve as controls. Loss of membrane integrity is reflected by signals migrating outside of the intact cell gate.

Fig. 3. Effect of different free chlorine concentrations on the culturability and membrane integrity of (A) E. coli and (B) E. faecalis suspensions along a humic acid turbidity gradient. Bacterial suspensions $\left(10^{5} \mathrm{CFU} \mathrm{mL}^{-1}\right)$ were mixed with humic acids prior to adding chlorine at indicated initial concentrations. Samples without chlorine and/or without humic acids served as controls. After incubation for $30 \mathrm{~min}$ and subsequent chlorine neutralization aliquots were spotted on nutrient agar plates (representative agar plates shown) or analyzed for membrane integrity by flow cytometry. Flow cytometric quantification of intact and membrane-damaged bacteria was transformed into a colour grid with intense green colour representing membrane intactness and intense red colour representing membrane damage. Transition states are indicated by a colour gradient. 
Fig. 4. Effect of different free chlorine concentrations on the culturability and membrane integrity of (A) E. coli and (B) E. faecalis suspensions along a chalk turbidity gradient. Bacterial suspensions $\left(10^{5} \mathrm{CFU} \mathrm{mL}^{-1}\right)$ were mixed with chalk (calcium carbonate) prior to adding chlorine at indicated initial concentrations. Samples without chlorine and/or without humic acids served as controls. After incubation for $30 \mathrm{~min}$ and subsequent chlorine neutralization aliquots were spotted on nutrient agar plates (representative agar plates shown) or analyzed for membrane integrity by flow cytometry. Flow cytometric quantification of intact and membrane-damaged bacteria was transformed into a colour grid with intense green colour representing membrane intactness and intense red colour representing membrane damage. Transition states are indicated by a colour gradient. 


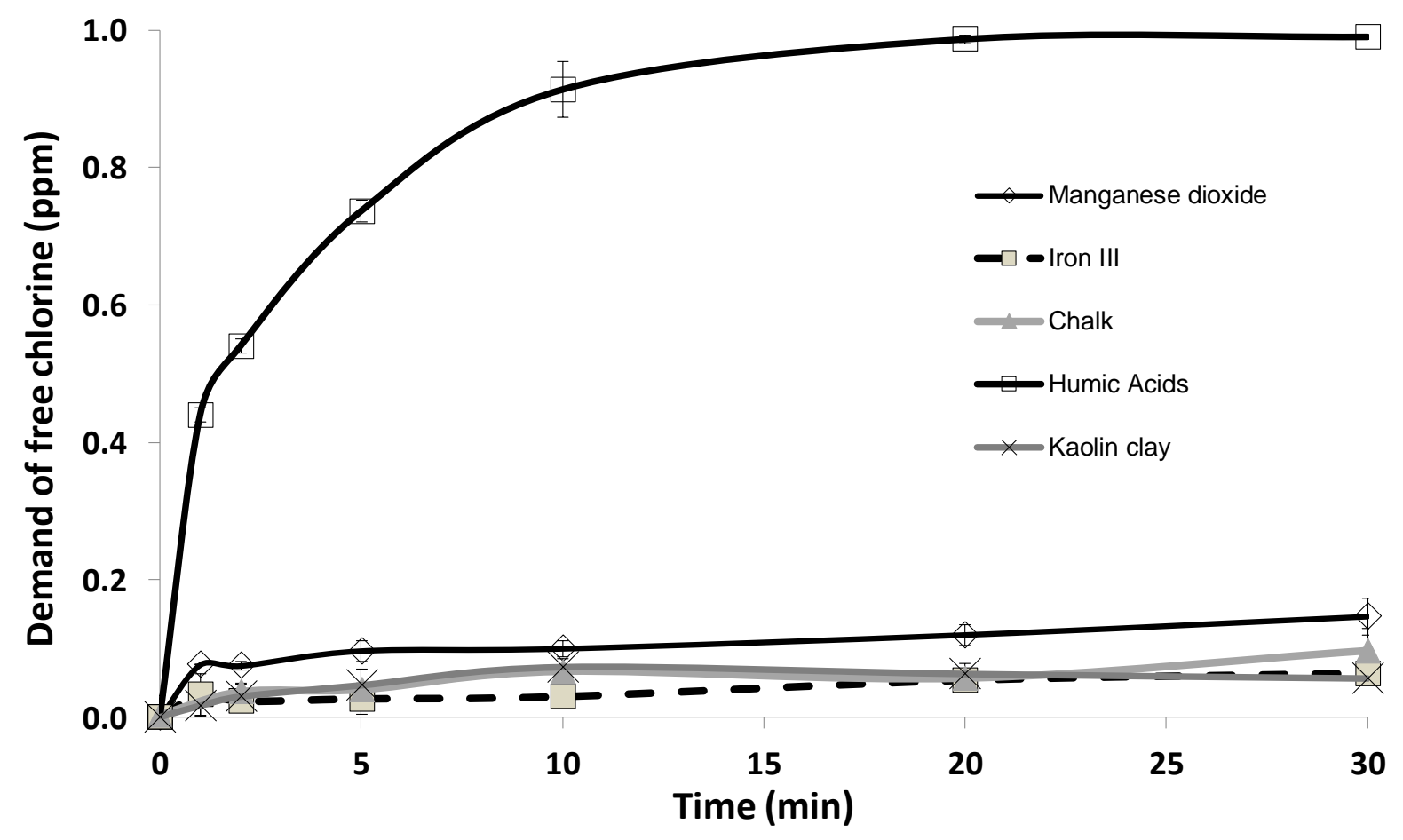

Fig. 1. Chlorine consumption kinetics of five selected TCMs (1 NTU each) mixed with chlorine (1 mg L ${ }^{-1}$ initial concentration at time point zero). Concentrations of free chlorine were measured at time points 0 and after 1,2, 5, 10, 20 and $30 \mathrm{~min}$. 
A
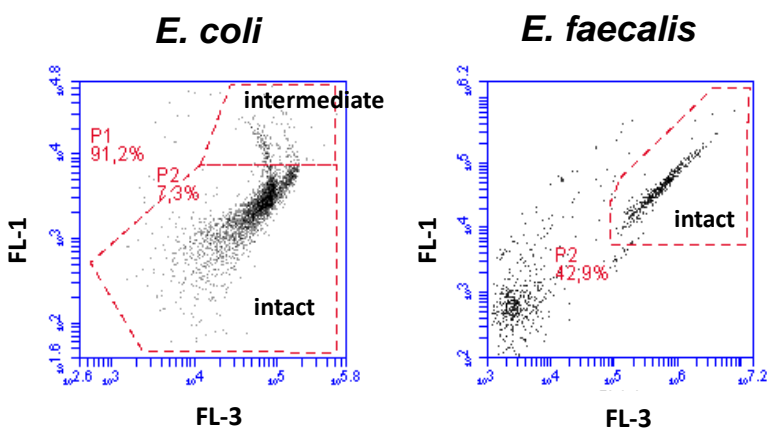

B

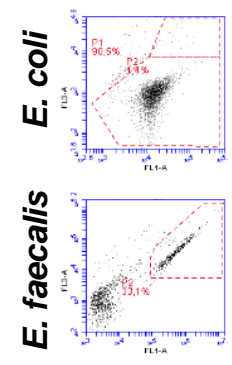

0
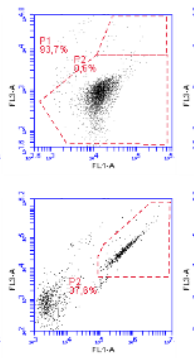

0.01
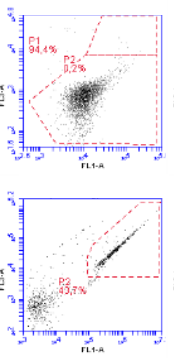

0.05
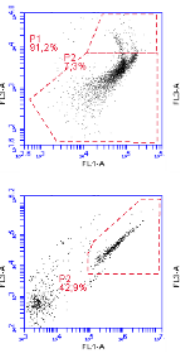

0.1
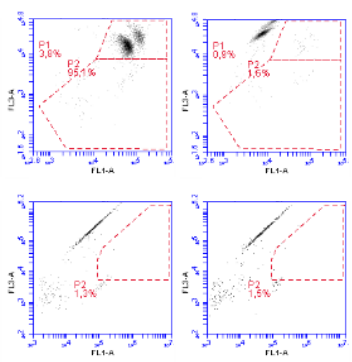

0.5
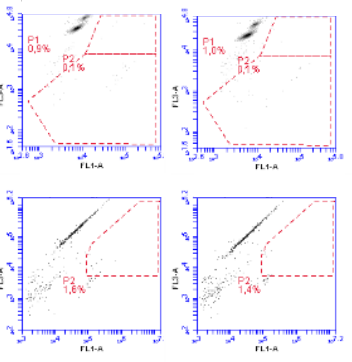

0.75

Chlorine concentration ( $\left.\mathrm{mg} \mathrm{L}^{-1}\right)$

Fig. 2. Effect of chlorine on flow cytometric profiles of E. coli and E. faecalis. (A) Gates used to assess the extent of membrane damage. Two gates (defined by dotted lines) were used in case of $E$. coli where a transition from intact via moderately damaged (intermediate) to strongly damaged bacteria could be well differentiated. One gate was used for E.faecalis as the transition from intact to damaged was more abrupt. (B) Change of FCM patterns after exposing bacteria to different chlorine concentrations for $30 \mathrm{~min}$ followed by neutralization of the disinfectant and membrane integrity staining. Non-treated suspensions without chlorine serve as controls. Loss of membrane integrity is reflected by signals migrating outside of the intact cell gate. 
A E. coli

\begin{tabular}{llllllll}
\multicolumn{1}{c}{ Free chlorine $\left(\mathrm{mg} \mathrm{L}^{-1}\right)$} \\
0 & 0.01 & 0.05 & 0.1 & 0.25 & 0.5 & 0.75
\end{tabular}

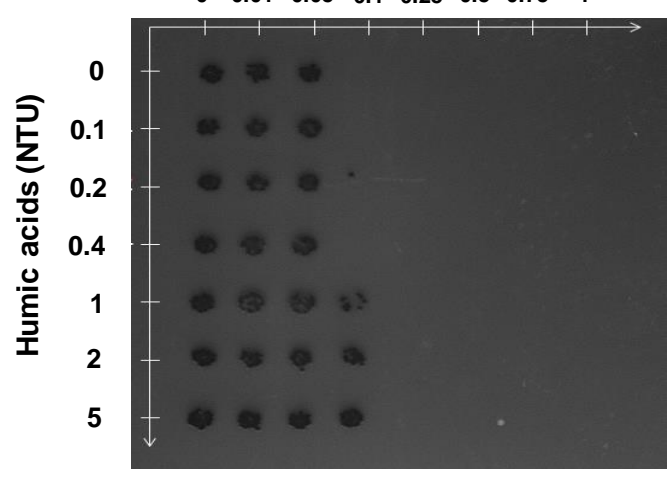

B E. faecalis

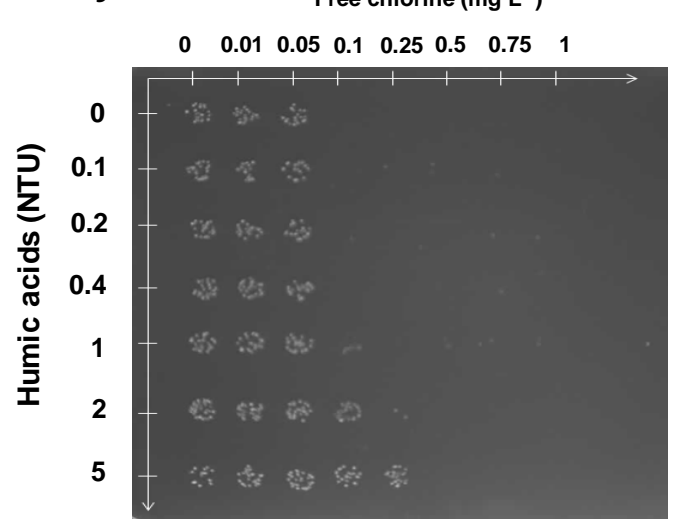

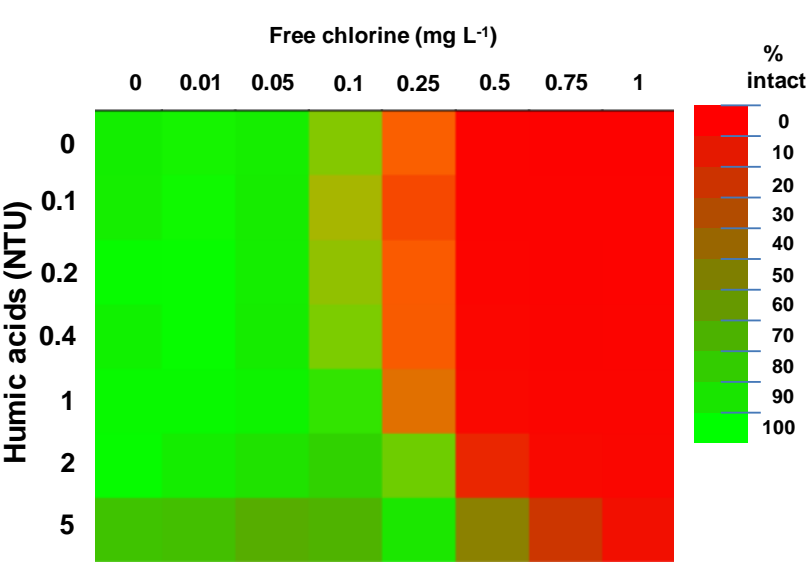

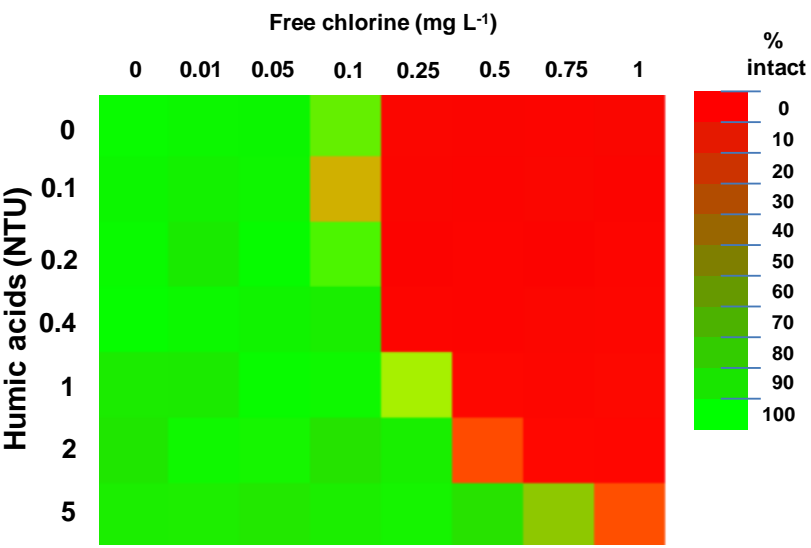

Fig. 3. Effect of different free chlorine concentrations on the culturability and membrane integrity of (A) E. coli and (B) E. faecalis suspensions along a humic acid turbidity gradient. Bacterial suspensions $\left(10^{5} \mathrm{CFU} \mathrm{mL}^{-1}\right)$ were mixed with humic acids prior to adding chlorine at indicated initial concentrations. Samples without chlorine and/or without humic acids served as controls. After incubation for $30 \mathrm{~min}$ and subsequent chlorine neutralization aliquots were spotted on nutrient agar plates (representative agar plates shown) or analyzed for membrane integrity by flow cytometry. Flow cytometric quantification of intact and membrane-damaged bacteria was transformed into a colour grid with intense green colour representing membrane intactness and intense red colour representing membrane damage. Transition states are indicated by a colour gradient. 
A E. coli

Free chlorine $\left(\mathrm{mg} \mathrm{L}^{-1}\right)$

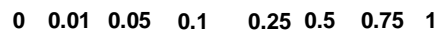

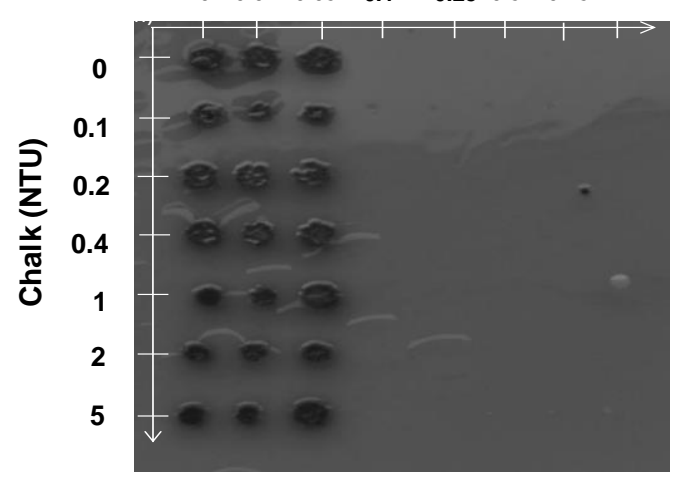

B E. faecalis

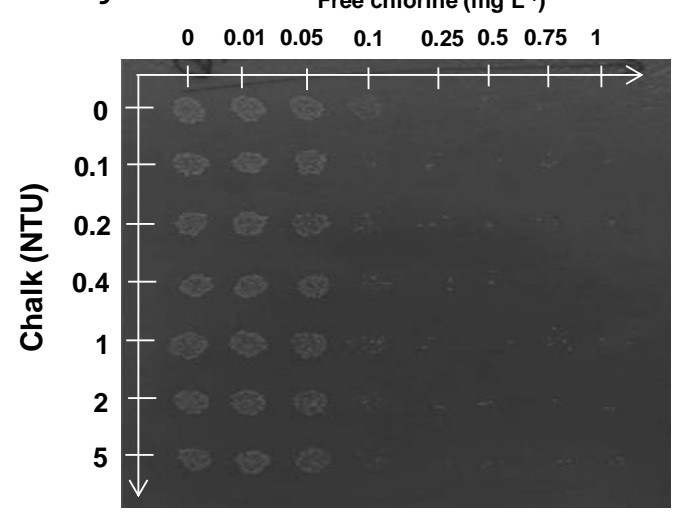

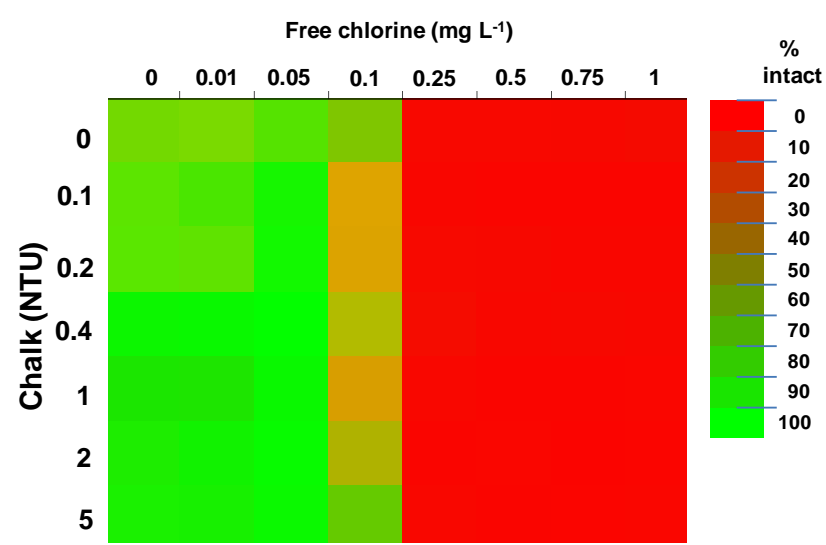

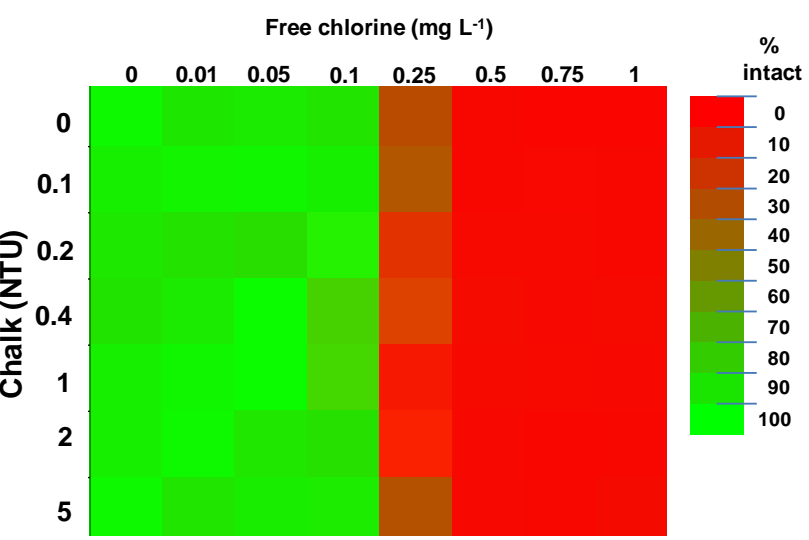

Fig. 4. Effect of different free chlorine concentrations on the culturability and membrane integrity of (A) E. coli and (B) E. faecalis suspensions along a chalk turbidity gradient. Bacterial suspensions $\left(10^{5} \mathrm{CFU} \mathrm{mL}^{-1}\right)$ were mixed with chalk (calcium carbonate) prior to adding chlorine at indicated initial concentrations. Samples without chlorine and/or without humic acids served as controls. After incubation for $30 \mathrm{~min}$ and subsequent chlorine neutralization aliquots were spotted on nutrient agar plates (representative agar plates shown) or analyzed for membrane integrity by flow cytometry. Flow cytometric quantification of intact and membrane-damaged bacteria was transformed into a colour grid with intense green colour representing membrane intactness and intense red colour representing membrane damage. Transition states are indicated by a colour gradient. 